\title{
The impact of tracheostomy timing on clinical outcomes and adverse events in intubated patients with infratentorial lesions: early versus late tracheostomy
}

\author{
Hua-Wei Huang ${ }^{1} \cdot$ Guo-Bin Zhang ${ }^{2} \cdot$ Ming Xu ${ }^{1} \cdot$ Guang-Qiang Chen ${ }^{1} \cdot$ Xiao-Kang Zhang ${ }^{2} \cdot$ Jun-Ting Zhang $^{2}$. \\ Zhen $\mathrm{Wu}^{2} \cdot$ Jian-Xin Zhou ${ }^{1}$ (i)
}

Received: 13 April 2020 / Revised: 18 May 2020 / Accepted: 17 June 2020 / Published online: 25 June 2020

(C) Springer-Verlag GmbH Germany, part of Springer Nature 2020

\begin{abstract}
We evaluated the association between the timing of tracheostomy and clinical outcomes in patients with infratentorial lesions. We performed a retrospective observational cohort study in a neurosurgical intensive care unit (ICU) at a tertiary academic medical center from January 2014 to December 2018. Consecutive adult patients admitted to the ICU who underwent resection of infratentorial lesions as well as tracheostomy were included for analysis. Early tracheostomy was defined as performed on postoperative days 1-10 and late tracheostomy on days 10-20 after operation. Univariate and multivariate analyses were used to compare the characteristics and outcomes between both cohorts. A total of 143 patients were identified, and 96 patients received early tracheostomy. Multivariable analysis identified early tracheostomy as an independent variable associated with lower occurrence of pneumonia (odds ratio, $0.25 ; 95 \%$ CI, $0.09-0.73 ; p=0.011$ ), shorter stays in ICUs (hazard ratio, $0.4 ; 95 \%$ CI, 0.3-0.6; $p=0.03$ ), and earlier decannulation (hazard ratio, $0.5 ; 95 \% \mathrm{CI}, 0.4-0.8 ; p=0.003$ ). However, no significant differences were observed between the early and late tracheostomy groups regarding hospital mortality $(p>0.999)$ and the modified Rankin scale after 6 months $(p=0.543)$. We also identified postoperative brainstem deficits, including cough, swallowing attempts, and extended tongue as well as GCS $<8$ at ICU admission as the risk factors independently associated with patients underwent tracheostomy. There is a significant association between early tracheostomy and beneficial clinical outcomes or reduced adverse event occurrence in patients with infratentorial lesions.
\end{abstract}

Keywords Adverse events $\cdot$ Clinical outcomes $\cdot$ Critical care $\cdot$ Infratentorial lesions $\cdot$ Timing of tracheostomy

\section{Introduction}

Patients with infratentorial lesions, including lesions in the brainstem, cerebellum, or both, are vulnerable to respiratory complications and death, and they consume scarce critical care resources [1]. Potential reasons for the increased risk of

Electronic supplementary material The online version of this article (https://doi.org/10.1007/s10143-020-01339-7) contains supplementary material, which is available to authorized users.

Jian-Xin Zhou

zhoujx_ttyy@sina.com

1 Department of Critical Care Medicine, Beijing Tiantan Hospital, Capital Medical University, South 4th Ring West Road 119, Fengtai District, Beijing 100070, People's Republic of China

2 Department of Neurosurgery, Beijing Tiantan Hospital, Capital Medical University, Beijing, China respiratory compromise include damage to the medullary respiratory center, posterior cranial nerves involved in airway protection, and reticular activating pathways that impair consciousness with secondary reduction of protective airway reflexes [2]. Therefore, optimizing airway management is crucial for improving clinical outcomes in patients with infratentorial lesions.

Tracheostomy is usually performed in critically ill patients who require prolonged mechanical ventilation. Tracheostomy has several established advantages over translaryngeal intubation, including reduced airway dead space and thus reduced work of breathing, facilitated weaning from mechanical ventilation, reduced undesired consequences of prolonged mechanical ventilation (e.g., ventilator-associated pneumonia and tracheal stenosis), convenient suctioning, and better patient comfort [3, 4]. However, tracheostomy is not risk-free, and the optimal timing to perform tracheostomy remains challenging. 
It is widespread critical care practice to perform tracheostomy after 2 or even 3 weeks of mechanical ventilation, often after weaning or extubation failure [4]. A recent meta-analysis of randomized clinical trials in a mixed intensive care unit (ICU) population found that early tracheostomy only displayed neutral results [5]. Although some data for early tracheostomy in neurocritical care patients are promising, these mostly cover patients with traumatic brain injury [6], subarachnoid hemorrhage [3], and stroke [4, 7]. Only two retrospective studies with very small sample sizes focused on the tracheostomy timing in patients with infratentorial lesions $[2,8]$. Goriachev et al. recommended that a tracheostomy should be performed 1-3 days after operation in patients with infratentorial tumors; however, this study did not explicitly evaluate the association between tracheostomy timing and clinical outcomes [8]. Qureshi et al. evaluated the association between tracheostomy timing and clinical outcomes in only 23 patients [2]. Thus, we sought to evaluate the effect of tracheostomy timing on clinical outcomes and the occurrence of adverse events (AEs) in patients undergoing resection of infratentorial lesions in a relatively large cohort.

\section{Methods}

\section{Study design, setting, and airway management protocol}

This retrospective observational cohort study was conducted in a neurosurgical ICU of the Beijing Tiantan Hospital, Capital Medical University, Beijing, China, from January 2014 to December 2018. Ethical approval was obtained from the Ethics Committee of Beijing Tiantan Hospital. This study did not cause any specific interventions, and clinical data were retrospectively extracted from electronic medical records; as such, the Ethics Committee waived the need for any consent.

Our hospital is a tertiary-care institution with 400 beds including $30 \mathrm{ICU}$ beds for neurosurgical patients. Decisions regarding weaning, extubation, re-intubation, and tracheostomy were made during morning rounds by certified full-time neurosurgeons and intensivists. The weaning protocol followed the European guidelines of weaning from mechanical ventilators in general ICU patients [9]. After the resolution of acute organ dysfunction and withdrawal of sedative drugs, the eligibility for a spontaneous breathing trial was assessed daily. Patients underwent a 30-min T-piece trial without continuous positive airway pressure to evaluate their readiness for extubation. In patients who passed this trial, consciousness, gag reflex, cough, and extended tongue function were assessed before extubation [10]. Extubation was considered delayed when patients were not extubated within $48 \mathrm{~h}$ of meeting the defined readiness criteria [11]. Extubation failure was defined as re-intubation with an endotracheal tube within
$72 \mathrm{~h}$ after extubation [12]. Regarding tracheostomy indications, the following criteria were used: (1) unrecoverable consciousness or airway protective ability in the short term, (2) prolonged mechanical ventilation, (3) difficulty of weaning, or (4) extubation failure [12]. Tracheostomies using the classic open surgical technique or percutaneous dilatation approach were performed in the ICU by neurointensive care physicians, neurosurgeons, or otorhinolaryngological surgeons. In our department, neurointensive care physicians and neurosurgeons adopted the dilation approach, while otorhinolaryngological surgeons used the classic open surgical technique. In our daily work, we did not observe any differences in complication occurrence in tracheostomies performed by neurointensive care physicians and neurosurgeons. Indications for decannulation were the termination of mechanical ventilation for at least $48 \mathrm{~h}$ and sufficient coughing and swallowing reflexes [3]. Detailed information on the airway management protocol is described in the online supplement (Supplemental Digital Content 1).

\section{Patient population}

Of the 1256 patients who underwent elective intubation for craniotomy involving the infratentorial region and who were admitted to the neurosurgical ICU for immediate postoperative and critical care, 256 patients with tracheostomies were enrolled in the present study. Patients under 18 years of age, with preexisting tracheostomy tubes, undergoing tracheostomy after day 20 due to unexpected complications, or undergoing elective intubations for operations that were routinely extubated successfully in the operating or recovery room were excluded. Thus, 143 patients with infratentorial lesions and tracheostomies remained and were dived into two groups based on the tracheostomy timing. Tracheostomies performed $1-10$ days or $>10$ days after intubation constituted criteria for the early and late group, respectively.

\section{Data collection}

Baseline and preoperative data were extracted from hospital records, including the nature, location, and size of the lesion as well as demographic characteristics, disease recurrence, obstructive hydrocephalus, and the presence of posterior cranial nerve injury, defined as clinical deficits localizing to cranial nerve nuclei or long tracts within the brainstem. The resection extent was extracted from surgical records. ICU admission data were extracted from nursing and hospital records, including the Glasgow coma scale (GCS) score upon ICU admission, time from admission to tracheostomy, GCS score at the time of tracheostomy, extubation attempts, cause of tracheostomy (airway or non-airway problem), and tracheostomy approach. 


\section{Outcome}

The primary outcomes were the occurrence of ventilatorassociated pneumonia (VAP) and other respiratory AEs. The secondary outcomes were modified Rankin scale (mRS) score 6 months after surgery, AEs other than pneumonia and respiratory AEs, hospital mortality, ICU length of stay (LOS), and time until decannulation. The mRS score was divided into a favorable (0-2) and unfavorable (3-6) neurological outcome. AEs comprised six categories: respiratory, cardiovascular, neurological, infectious, tracheostomy-related, and ventilator-associated pneumonia. Ventilator-associated pneumonia was distinguished from respiratory AEs due to its clinical importance. Supplemental Digital Content 1 describes in detail the assessment of AEs. The time until decannulation referred to the time between performing the tracheostomy until decannulation.

\section{Statistical analysis}

In the descriptive statistics, numerical or ordered variables are presented as median values with interquartile (Q1-Q3) ranges, and significance was tested using the Mann-Whitney $U$ test. Binary variables were analyzed with the chi-square test and binary logistic regression for multivariable analysis.

Baseline, preoperative, surgical, and ICU admission data were considered dependent variables, and independent variables were AEs. Groups were compared using the log-rank test and pointwise $95 \%$ confidence intervals (CIs). We employed a multivariable Cox proportional hazards regression model with backward stepwise selection (likelihood ratio) to identify independent predictors for outcome variables. All statistical tests were two-tailed, and $p<0.05$ was considered statistically significant. To remove potential confounding factors, we performed a multivariable analysis to determine independent risk factors and included variables identified in the univariable analysis with $p<0.1$. Data were analyzed using SPSS v22.0.

\section{Results}

Of the 1256 patients admitted to the neurosurgical ICU who underwent elective intubation for craniotomy involving the infratentorial region, 1000 patients were extubated successfully and 256 patients were undergone tracheostomies. Finally, 724 patients in extubated successfully group and 143 patients in tracheostomy group were analyzed according to inclusion and exclusion criteria. More than $90 \%$ of adult patients were extubated successfully before postoperative day 5 (678/724 patients; Supplemental Fig. 1, Supplemental Digital Content 2). Of the enrolled 143 patients, 96 and 47 patients underwent tracheostomy on postoperative days $1-10$ and 11-20, respectively. The patients' demographics and admission characteristics are presented in Table 1. Except for extubation trials, no significant differences in baseline or clinical variables were observed between the early and late tracheostomy groups. Patients with late tracheostomies had significantly more extubation trials $(51.5 \%$ vs. $19.8 \% ; p<0.001)$ prior to tracheostomy. Of the 43 patients with extubation trials, only 11 patients $(25.6 \%)$ were extubated within 2 days of meeting the extubation criteria, whereas extubation delay was registered in 32 patients $(74.4 \%)$. Most extubations (23/43 patients) were attempted on postoperative days $6-8$.

\section{Effects of tracheostomy timing on pneumonia and other respiratory AEs}

Compared with the early tracheostomy group, we found an increased occurrence of pneumonia (odds ratio [OR], 1.27 95\% CI, 1.07-1.51; $p=0.017$; Table 2) in the late tracheostomy group. We further investigated whether pneumonia developed prior to or after tracheostomy. Patients with early tracheostomy had lower pneumonia incidences both before (49\% vs. $83 \%, p<0.001)$ and after $(4.3 \%$ vs. $19.8 \%, p=0.014$; Table 2) tracheostomy. The multivariable analysis identified early tracheostomy (OR, $0.25 ; 95 \% \mathrm{CI}, 0.09-0.73 ; p=0.11)$, primary lesion (OR, $0.32 ; 95 \% \mathrm{CI}, 0.13-0.80 ; p=0.015)$, and $\mathrm{GCS} \geq 8$ at the time of tracheostomy (OR, $0.25 ; 95 \% \mathrm{CI}$, $0.09-0.73 ; p=0.14)$ to be associated with the development of pneumonia (Nagelkerke $R^{2}=0.262$; Table 3 ). The analysis also revealed increased occurrences of respiratory (OR, 2.04; 95\% CI, 1.33-3.14; $p=0.001)$ and neurological (OR, 2.21; 95\% CI, $1.10-4.47 ; p=0.025)$ AEs in the late tracheostomy group; no differences were observed regarding other AEs between the tracheostomy groups.

\section{Effect of tracheostomy timing on ICU LOS}

We observed that ICU LOS was significantly shorter in the early (median, 9 days; $95 \%$ CI, 3-16 days) compared with the late (median, 18 days; 95\% CI, 13-27 days) tracheostomy group. Multivariable analysis revealed early tracheostomy (hazard ratio [HR], 0.4; 95\% CI, 0.3-0.6; $p=0.03$ ), tracheostomy due to airway problems (HR, $0.32 ; 95 \% \mathrm{CI}, 0.21-0.50$; $p<0.001$ ), no pneumonia (HR, $0.59 ; 95 \%$ CI, $0.39-0.89 ; p=$ 0.012), and no infectious AEs (HR, 0.47; 95\% CI, 0.31-0.69; $p<0.001)$ as independent factors for shorter ICU LOS (Supplemental Table 1, Supplemental Digital Content 3).

\section{Effect of tracheostomy timing on time to decannulation}

Decannulation occurred significantly earlier in the early group than in the late tracheostomy group (median, 38 days; $95 \% \mathrm{CI}$, 26-45 days vs. median, 52 days; $95 \%$ CI, 42-59 days; 
Table 1 Patient characteristics in relation to tracheostomy timing

\begin{tabular}{|c|c|c|c|}
\hline Variable & Early $(n=96)$ & Late $(n=47)$ & $p$ value \\
\hline Age (years) & $42.7 \pm 14.3$ & $45.3 \pm 15.2$ & 0.331 \\
\hline Gender (male/female) & $54 / 42$ & $20 / 27$ & 0.124 \\
\hline \multicolumn{3}{|l|}{ Medical history, $n(\%)$} & 0.107 \\
\hline Hypertension & $21(21.9 \%)$ & $13(27.7 \%)$ & \\
\hline Diabetes mellitus & $10(10.4 \%)$ & $4(8.5 \%)$ & \\
\hline Coronary artery disease & $1(1.0 \%)$ & $3(6.4 \%)$ & \\
\hline Pulmonary disease & $2(2.1 \%)$ & $3(6.4 \%)$ & \\
\hline Stroke & $2(2.1 \%)$ & $0(0 \%)$ & \\
\hline \multicolumn{3}{|l|}{ Nature of lesion, $n(\%)$} & 0.622 \\
\hline Glioma & $27(28.1 \%)$ & $14(29.8 \%)$ & \\
\hline Meningioma & $29(30.2 \%)$ & $14(29.8 \%)$ & \\
\hline Neurilemmoma & $19(19.8 \%)$ & $6(12.8 \%)$ & \\
\hline Vascular malformation & $2(2.1 \%)$ & $3(6.4 \%)$ & \\
\hline Others & $19(19.8 \%)$ & $10(21.3 \%)$ & \\
\hline \multicolumn{3}{|l|}{ Lesion location, $n(\%)$} & 0.14 \\
\hline Brain stem & $41(42.7 \%)$ & $19(40.4 \%)$ & \\
\hline Jugular and magnum foramen & $11(11.5 \%)$ & $7(14.9 \%)$ & \\
\hline Petroclival region and CPA & $26(27.1 \%)$ & $14(29.8 \%)$ & \\
\hline Cerebellum and forth ventricle & $17(17.7 \%)$ & $7(14.9 \%)$ & \\
\hline Recurrent lesion, $n(\%)$ & $24(25.0 \%)$ & $12(25.5 \%)$ & 0.945 \\
\hline Preoperative hydrocephalus, $n(\%)$ & $38(39.6 \%)$ & $14(29.8 \%)$ & 0.253 \\
\hline Preoperative brainstem deficits, $n(\%)$ & $56(58.3 \%)$ & $27(57.4 \%)$ & 0.920 \\
\hline Gross-total resection, $n(\%)$ & $64(66.7 \%)$ & $32(68.1 \%)$ & 0.865 \\
\hline \multicolumn{3}{|l|}{ Postoperative brainstem deficits, $n(\%)$} & 0.237 \\
\hline Cough & $73(76.0 \%)$ & $31(66.0 \%)$ & \\
\hline Swallowing attempts & $30(31.3 \%)$ & $21(44.7 \%)$ & \\
\hline Extended tongue & $22(22.9 \%)$ & $12(25.5 \%)$ & \\
\hline Largest lesion dimension $(\mathrm{mm})$ & $42.7 \pm 14.3$ & $45.3 \pm 15.2$ & 0.331 \\
\hline GCS $<8$ at ICU admission, $n(\%)$ & $12(12.5 \%)$ & $9(19.1)$ & 0.291 \\
\hline Extubation trial, $n(\%)$ & $19(19.8 \%)$ & $24(51.5 \%)$ & $<0.001$ \\
\hline GCS $<8$ at the time of tracheostomy, $n(\%)$ & $13(13.5 \%)$ & $8(17.0 \%)$ & 0.581 \\
\hline \multicolumn{3}{|l|}{ Cause of tracheostomy, $n(\%)$} & 0.054 \\
\hline Non-airway problem & 22 & 18 & \\
\hline Airway problem & 74 & 29 & \\
\hline \multicolumn{3}{|l|}{ Approach of tracheostomy, $n(\%)$} & 0.561 \\
\hline Percutaneous dilatation tracheostomy & 84 & 40 & \\
\hline Open surgery & 11 & 7 & \\
\hline
\end{tabular}

$C P A$ cerebellopontine angle, GCS Glasgow coma scale, $I C U$ intensive care unit

Data are given as mean. Data comparisons were made with Mann-Whitney $U$ test or chi-square test, where applicable $p<0.001)$. Multivariable analysis revealed early tracheostomy (HR, $0.5 ; 95 \%$ CI, $0.4-0.8 ; p=0.003$ ) and tracheostomy due to airway problems (HR, $0.42 ; 95 \% \mathrm{CI}, 0.28-0.63$; $p<0.001)$ as independent variables associated with early decannulation, whereas no respiratory AEs (HR, 1.78; 95\% CI, $1.22-2.60 ; p=0.003)$ were associated with late decannulation (Supplemental Table 2, Supplemental Digital Content 4).

\section{Effect of tracheostomy timing on hospital survival and $\mathrm{mRS}$ scores}

No significant differences were observed in hospital mortality between both tracheostomy groups $(p>0.99)$. Also, the analysis of outcome variables did not reveal any significant differences regarding $\mathrm{mRS}$ scores $(p=$ $0.543)$. 
Table 2 Clinical outcomes in relation to tracheostomy timing

\begin{tabular}{|c|c|c|c|c|}
\hline Variable & Early $(n=96)$ & Late $(n=47)$ & $p$ value & OR $(95 \% \mathrm{CI})$ \\
\hline Patients with respiratory AE, $n(\%)$ & $25(26)$ & $25(53.2)$ & 0.001 & $2.04(1.33-3.14)$ \\
\hline Patients with pneumonia, $n(\%)$ & $66(68.8)$ & $41(87.2)$ & 0.017 & $1.27(1.07-1.51)$ \\
\hline Patients with pneumonia prior to tracheostomy, $n(\%)$ & $47(49.0)$ & $39(83.0)$ & $<0.001$ & $1.70(1.33-2.16)$ \\
\hline Patients with pneumonia post tracheostomy, $n(\%)$ & $19(19.8)$ & $2(4.3)$ & 0.014 & $0.22(0.05-0.89)$ \\
\hline Patients with cardiovascular AE, $n(\%)$ & $45(46.9)$ & $29(61.7)$ & 0.096 & $1.32(0.97-1.80)$ \\
\hline Patients with neurologic AE, $n(\%)$ & $12(12.5)$ & $13(27.7)$ & 0.025 & $2.21(1.10-4.47)$ \\
\hline Patients with infectious AE, $n(\%)$ & $37(38.5)$ & $23(48.9)$ & 0.237 & $1.27(0.86-1.87)$ \\
\hline Patients with AE related to tracheostomy, $n(\%)$ & $7(7.3)$ & $3(6.4 \%)$ & $>0.999$ & $0.88(0.24-3.23)$ \\
\hline ICU LOS & $9(3-16)$ & $18(13-27)$ & $<0.001$ & \\
\hline ICU LOS before tracheostomy & $4(2-6)$ & $14(10-17)$ & $<0.001$ & \\
\hline ICU LOS after tracheostomy & $2(0-10)$ & $4(1-11)$ & 0.499 & \\
\hline Hospital LOS & $32(25-41)$ & $41(34-61)$ & $<0.001$ & \\
\hline Time to decannulation (days) & $38(26-45)$ & $52(42-59)$ & $<0.001$ & \\
\hline Death, $n(\%)$ & $5(5.2)$ & $3(6.4)$ & $>0.999$ & $0.82(0.20-3.27)$ \\
\hline mRS 6 months, $n(\%)$ & & & 0.543 & $1.19(0.68-2.08)$ \\
\hline $0-2$ & $72(75)$ & $33(70.2)$ & & \\
\hline $3-6$ & $24(25)$ & $14(29.8)$ & & \\
\hline
\end{tabular}

$O R$ odds ratio, $m R S$ modified Rankin scale, $A E$ adverse event, $L O S$ length of stay

Data are given as means unless stated otherwise. Data comparisons were made with Mann-Whitney $U$ test, where applicable

\section{Factors related to the decision to perform a tracheostomy}

Table 4 provides a comparison of clinical characteristics between patients who were successfully extubated and patients who underwent tracheostomy. Brainstem involvement, jugular and magnum foramen involvement, cerebellum and forth ventricle involvement, recurrent lesion, postoperative brainstem deficits, including cough, swallowing attempts, and extended tongue as well as GCS $<8$ at ICU admission
Table 3 Univariate and multivariate analysis of variable associated pneumonia (Nagelkerke $R^{2}=0.262$ )

\begin{tabular}{|c|c|c|c|c|}
\hline \multirow[b]{2}{*}{ Variable } & \multicolumn{2}{|l|}{ Univariate analysis } & \multicolumn{2}{|c|}{ Multivariate analysis } \\
\hline & OR $(95 \%$ CI $)$ & $p$ & OR $(95 \% \mathrm{CI})$ & $p$ \\
\hline Early tracheostomy & $0.44(0.20-0.94)$ & 0.02 & $0.25(0.09-0.73)$ & 0.011 \\
\hline Age $>65$ years & $1.049(1.01-1.09)$ & 0.43 & & \\
\hline$\geq 1$ comorbidities & $1.13(0.90-1.43)$ & 0.33 & & \\
\hline Malignant lesion & $1.13(0.91-1.40)$ & 0.32 & & \\
\hline Lesion in brain stem & $1.14(0.85-1.53)$ & 0.41 & & \\
\hline Primary lesion & $0.82(0.62-1.06)$ & 0.08 & $0.32(0.13-0.80)$ & 0.015 \\
\hline Preoperative hydrocephalus & $1.21(0.76-1.92)$ & 0.44 & & \\
\hline Gross-total resection & $1.02(0.60-1.74)$ & 0.95 & & \\
\hline Lesion size $>3 \mathrm{~cm}$ & $1.16(0.86-1.56)$ & 0.36 & & \\
\hline Postoperative brainstem deficits & $1.05(0.45-2.46)$ & 0.91 & & \\
\hline $\mathrm{GSC} \geq 8$ at ICU admission & $0.89(0.73-1.07)$ & 0.14 & & \\
\hline GSC $\geq 8$ at the time of tracheostomy & $0.84(0.69-1.02)$ & 0.03 & $0.25(0.09-0.75)$ & 0.014 \\
\hline Extubation trial & $0.79(0.42-1.48)$ & 0.44 & & \\
\hline Open surgical tracheostomy & $1.20(1.10-1.31)$ & 0.02 & 0 & 0.998 \\
\hline Neurologic AE & $1.16(0.53-2.54)$ & 0.72 & & \\
\hline
\end{tabular}

$O R$ odds ratio, GCS Glasgow coma scale, $I C U$ intensive care unit, $A E$ adverse event

Data comparisons were made with chi-square test for univariable analysis, and binary logistic regression with stepwise exclusion was used for multivariable analysis 
Table 4 Baseline characteristics of patients who were successful extubation and received tracheostomy

\begin{tabular}{|c|c|c|c|}
\hline Variable & $\begin{array}{l}\text { Successfully } \\
\text { extubated } \\
(n=724)\end{array}$ & $\begin{array}{l}\text { Tracheostomy } \\
(n=143)\end{array}$ & $p$ value \\
\hline Age (years) & $44.0 \pm 14.5$ & $43.6 \pm 14.6$ & 0.711 \\
\hline Gender (male/female) & $378 / 346$ & $74 / 69$ & 0.854 \\
\hline History of hypertension, $n(\%)$ & $176(24.3 \%)$ & $34(23.8 \%)$ & 0.892 \\
\hline History of diabetes mellitus, $n(\%)$ & $74(10.2 \%)$ & $14(9.8 \%)$ & 0.876 \\
\hline History of coronary artery disease, $n(\%)$ & $16(2.2 \%)$ & $4(2.8 \%)$ & 0.902 \\
\hline History of pulmonary disease, $n(\%)$ & $23(3.2 \%)$ & $5(3.5 \%)$ & 0.843 \\
\hline History of stroke, $n(\%)$ & $8(1.1 \%)$ & $2(1.4 \%)$ & $>0.999$ \\
\hline \multicolumn{4}{|l|}{ Nature of lesion, $n(\%)$} \\
\hline Glioma & $191(26.4 \%)$ & $41(28.6 \%)$ & 0.572 \\
\hline Meningioma & $244(33.7 \%)$ & $43(30.1 \%)$ & 0.399 \\
\hline Neurilemmoma & $129(17.8 \%)$ & $25(17.5 \%)$ & 0.924 \\
\hline Vascular malformation & $23(3.2 \%)$ & $5(3.5 \%)$ & $>0.999$ \\
\hline Others & $137(18.9 \%)$ & $29(20.3 \%)$ & 0.706 \\
\hline \multicolumn{4}{|l|}{ Lesion involvement, $n(\%)$} \\
\hline Brainstem & $203(28.0 \%)$ & $60(42.0 \%)$ & 0.001 \\
\hline Jugular and magnum foramen & $50(6.9 \%)$ & $18(12.6 \%)$ & 0.021 \\
\hline Petroclival region and CPA region & $275(38.0 \%)$ & $40(28.0 \%)$ & 0.023 \\
\hline Cerebellum and forth ventricle & $190(26.2 \%)$ & $24(16.8 \%)$ & 0.017 \\
\hline Recurrent lesion, $n(\%)$ & $129(17.8 \%)$ & $36(25.2 \%)$ & 0.041 \\
\hline Preoperative hydrocephalus, $n(\%)$ & $280(38.7 \%)$ & $52(36.4 \%)$ & 0.603 \\
\hline Gross-total resection, $n(\%)$ & $499(68.9 \%)$ & $96(67.1 \%)$ & 0.673 \\
\hline \multicolumn{4}{|l|}{ Postoperative brainstem deficits, $n(\%)$} \\
\hline Cough & $98(13.5 \%)$ & $104(72.7 \%)$ & $<0.001$ \\
\hline Swallowing attempts & $113(15.6 \%)$ & $51(35.7 \%)$ & $<0.001$ \\
\hline Extended tongue & $48(6.6 \%)$ & $34(23.8 \%)$ & $<0.001$ \\
\hline GCS $<8$ at ICU admission, $n(\%)$ & $59(8.1 \%)$ & $21(14.7)$ & 0.014 \\
\hline
\end{tabular}

$C P A$ cerebellopontine angle, GCS Glasgow coma scale, ICU intensive care unit

Data are given as mean. Data comparisons were made with Mann-Whitney $U$ test or chi-square test, where applicable

were significantly different among the two groups. In multivariate analysis (Table 5), risk factors independently associated with patients who underwent tracheostomy were postoperative brainstem deficits, including cough (OR, 18.09; 95\% CI, 11.26-29.06; $p<0.001$ ), swallowing attempts (OR, 2.75; 95\% CI, 1.65-4.58; $p<0.001$ ), and extended tongue (OR, 3.70; 95\% CI, 1.97-7.03; $p<0.001)$ as well as GCS $<8$ at ICU admission (OR, 5.95; 95\% CI, 2.90-12.22; $p<0.001$ ).

\section{Discussion}

The present study examined the value of early versus late tracheostomy in neurosurgical patients who underwent resection of infratentorial lesions and required an artificial airway and/or ventilatory support. To our knowledge, this is the first cohort study to address this specific problem. Our findings suggest that early tracheostomy is associated with a lower incidence of respiratory complications, shorter ICU LOS, and earlier decannulation.

The effects of early tracheostomy on critically ill patients are intensely debated $[13,14]$. Recent meta-analyses of randomized controlled trials in critically ill patients did not find obvious benefits from early tracheostomies [5]; however, early tracheostomies appear to manifest their importance in neurological contexts $[3,4,6,12,15]$. The trial SETPOINT (Stroke-Related Early Tracheostomy vs. Prolonged Intubation) performed by Bosel et al. found that early tracheostomy resulted in less sedation and lower mortality in patients with severe hemorrhagic and ischemic stroke [4]. Jeon et al. reported that early tracheostomy can reduce the incidence of VAP, ventilation duration, and ICU LOS [12]. Chen et al. also demonstrated that early tracheostomy may decrease hospital LOS and costs [16]. However, these studies did not only focus on patients with infratentorial lesions. Among brain-injured patients, patients with infratentorial 
Table 5 Univariate and multivariate analysis of variable associated tracheostomy (Nagelkerke $R^{2}=0.435$ )

\begin{tabular}{|c|c|c|c|c|}
\hline \multirow[b]{2}{*}{ Variable } & \multicolumn{2}{|l|}{ Univariate analysis } & \multicolumn{2}{|l|}{ Multivariate analysis } \\
\hline & OR $(95 \% \mathrm{CI})$ & $p$ & OR $(95 \% \mathrm{CI})$ & $p$ \\
\hline \multicolumn{5}{|l|}{ Lesion involvement, $n(\%)$} \\
\hline Brainstem & $1.24(1.07-1.44)$ & 0.001 & $0.79(0.37-1.71)$ & 0.553 \\
\hline Jugular and magnum foramen & $1.07(1.00-1.14)$ & 0.021 & $0.82(0.08-8.42)$ & 0.864 \\
\hline Petroclival region and CPA region & $0.86(0.77-0.97)$ & 0.023 & $0.52(0.31-0.87)$ & 0.013 \\
\hline Cerebellum and forth ventricle & $0.89(0.81-0.97)$ & 0.017 & $0.50(0.27-0.90)$ & 0.022 \\
\hline Recurrent lesion, $n(\%)$ & $1.10(0.99-1.22)$ & 0.041 & $1.50(0.87-2.59)$ & 0.146 \\
\hline \multicolumn{5}{|l|}{ Postoperative brainstem deficits, $n(\%)$} \\
\hline Cough & $3.17(2.42-4.15)$ & $<0.001$ & $18.09(11.26-29.06)$ & $<0.001$ \\
\hline Swallowing attempts & $1.31(1.16-1.49)$ & $<0.001$ & $2.75(1.65-4.58)$ & $<0.001$ \\
\hline Extended tongue & $1.23(1.12-1.35)$ & $<0.001$ & $3.70(1.94-7.03)$ & $<0.001$ \\
\hline GCS $<8$ at ICU admission, $n(\%)$ & $1.08(1.00-1.16)$ & 0.014 & $5.95(2.90-12.22)$ & $<0.001$ \\
\hline
\end{tabular}

OR odds ratio, GCS Glasgow coma scale, ICU intensive care unit, $C P A$ cerebellopontine angle

Data comparisons were made with chi-square test for univariable analysis, and binary logistic regression with stepwise exclusion was used for multivariable analysis lesions are unique in their presentations and outcomes. Lesions in or near the brainstem may precipitate central respiratory dysfunction or posterior cranial nerve injury and may cause higher risks of extubation failure and death [1]. Goriachev et al. recommended that a tracheostomy should be performed 1-3 days after operation in patients with severe bulbar disorders or persistent coma, but did not explicitly evaluate the association between tracheostomy timing and clinical outcomes [8]. Qureshi et al. suggested that the right timing of tracheostomy is on days $8-10$ of mechanical ventilation, as performing tracheostomy at this time is most likely neither a futile procedure (low risk of death) nor an unnecessary procedure (high probability of extubation failure) [3]. However, they only evaluated the association between tracheostomy timing and clinical outcomes in 23 patients [3]. Precisely this key issue was addressed by our research.

There is little consensus on what is considered "early" and "late" tracheostomy. In critically ill patients, early tracheostomy varies between 2 and 10 days after mechanical ventilation, whereas late tracheostomy occurs after 14 days [14, 17-19]. Previous studies in neurocritical patients defined early tracheostomy as ranging from 1-3 days after ICU admission [6] to $1-10$ days after mechanical ventilation $[10,12]$. Different definitions complicate the interpretation of results. Tracheostomy timing of neurocritical patients must consider both weaning from mechanical ventilation and recovery from intracranial injury. Different types of brain-injured patients present with distinct features. Patients with severe traumatic brain injury cannot regain consciousness within a short time; therefore, the definition of "early" might be more bold, even within $72 \mathrm{~h}$ after traumatic brain injury [6]. Patients undergoing resection of infratentorial lesions have a relatively low mortality $(6 \%)$ and are largely conscious. Considering that tracheostomy is invasive, the definition of "early" might be relatively conservative. Furthermore, weaning and extubation in these patients are closely related to the resolution of brain edemas, which peak within 7 days after injury [20]. Before and around this peak is the time to improve brainstem functions, as afterwards the short-term possibility of weaning or extubation is very small. Therefore, we selected postoperative day 10 as the cutoff point, in agreement with studies investigating general patient populations.

By delaying extubation in the late tracheostomy group in our study, physicians hoped to increase the success rate of extubation (Table 1). Ventilated brain-injured patients are often affected by delayed extubation, as weaning is generally successful; however, extubation fails in approximately 30 $40 \%$ of cases [21-23]. Namen et al. found that neurosurgical patients with GCS scores $\geq 8$ at extubation were associated with a $75 \%$ extubation success rate, increasing $39 \%$ for each improvement point [24]. In the present study, we focused on patients after resection of infratentorial lesions, most of whom were in a good conscious state, but in a poor state regarding airway protection. Moreover, Coplin et al. found that basing extubation delay solely on the patient's level of consciousness causes an increase in pneumonia and does not decrease extubation failure [11]. It is still unclear whether braininjured patients who meet the weaning criteria must remain intubated for airway protection [25, 26]. Given the higher mortality associated with re-intubation [27], as well as the broader definition of the "time window" of extubation failure (re-intubation within 24-72 h or up to 7 days) [27], a 48-h "grace period" before extubation is sometimes allowed [11]. Nevertheless, only $25.6 \%$ of our patients were extubated without delay. The reason for our more conservative extubation was that patients with infratentorial lesions are at extremely 
high risks of extubation failure, with a reported value of $67 \%$ [2]. The causes of failure in our patients consisted of more airway than non-airway failures (103 vs. 40). Therefore, we adopted a strategy with delayed extubation following brain edema resolution and brainstem recovery. According to our clinical experience, proper extubation delay can improve extubation success rates and prevent unnecessary tracheostomies. Therefore, early tracheostomies within 10 days might give these patients a grace period for extubation and will not cause excessive delays.

Pneumonia is a commonly observed complication in $75 \%$ of our patients. According to the largest prospective randomized controlled trial, early tracheostomy does not decrease the ventilator-associated pneumonia incidence in mixed ICU patients [14]. However, our study demonstrated that early tracheostomy was associated with a decreased occurrence of pneumonia and other respiratory AEs. Two potential explanations exist. First, protective airway functions, especially the ability to clear secretions by coughing and swallowing, are frequently impaired in our patients. Early tracheostomy might facilitate earlier suctioning and reduce aspiration risk by decreasing extubation attempts. Second, the significant group differences regarding the development of pneumonia before tracheostomy can be explained by the longer extubation delay in patients with late tracheostomy. Although the extubation delay by the "grace period" might partially avoid unnecessary tracheostomies, we must balance between possible short-term recoverability of brainstem functions and the risk of pneumonia due to delayed extubation. Furthermore, our study also demonstrated that early tracheostomy was associated with earlier decannulation, which might only be a result of unnecessary early tracheostomies. This is a potential bias of early tracheostomy; however, no patient with an early tracheostomy was successfully decannulated before day 14 after admission, which, in clinical routine, is regarded as the time point to consider tracheotomy in patients without an extubation plan for the following days. Thus, the earlier a tracheostomy is performed, the earlier the comprehensive rehabilitation therapy can begin. Intense postoperative rehabilitation can improve swallowing functions, which is especially helpful for patients with infratentorial lesions. In mixed ICU and neurocritical patients, improved ventilator weaning may have caused decreases in ICU LOS, as described in the literature [3, 12-14, $28,29]$. Patients weaned from ventilators are also closer to potential or actual hospital discharge, which can translate into shorter LOS $[28,30,31]$.

In the present study, early tracheostomy had no beneficial effects on hospital mortality. Several meta-analyses focusing on critically ill patients and acutely severe brain-injured patients produced inconsistent results [5, 32-35]. Compared with the above-mentioned patients, our patients (with intense rehabilitation) often return to an acceptable quality of life and have a relatively low hospital mortality $(7 \%)$; as such, there was minimal opportunity for further improvement. This finding could also explain why our patients were more likely to receive early tracheostomy $(67 \%)$ in comparison with previous studies $[3,12,14]$. To be more specific, high mortality correlates with a decreased use of advanced life support [36]. Hence, our patients exhibited a positive attitude and preference to receiving early tracheostomy. In addition, tracheostomy is an invasive procedure that might increase intracranial pressure and reduce cerebral perfusion, which contributes to secondary neurological damage $[37,38]$. Our study demonstrated that the timing of tracheostomy was not associated with increased unfavorable neurological outcomes. However, vital signs should be closely monitored during tracheostomies.

We also used a multivariable logistic regression model to identify the predictors associated with tracheostomized patients. We proposed that patients with infratentorial lesions who had postoperative brainstem deficits and GCS $<8$ might often suffered from tracheostomy (extubation failure). In order to avoid multiple extubation failure resulting in late tracheostomy, earlier performance of tracheostomy might be recommended in the clinical practice, especially in patients with risk factors. However, the causality of the relationship between tracheostomy timing and clinical outcomes remains unproven in our retrospective observational study. Randomized controlled trials exploring the tracheostomy timing on patients' outcomes are warranted and would provide evidence-based recommendations on this issue. In general, though, the present study provided important data for the potential benefited population and timing of tracheostomy in patients with infratentorial lesions. In patients with infratentorial lesions, early tracheostomy may not only provide patients timely airway protection but may also alleviate ICU support and accelerate comprehensive rehabilitation therapy.

Although this study comprised the largest series of patients with infratentorial lesions to have undergone tracheostomy, it has several limitations. First, our study is limited by its retrospective observational design and the lack of prior objectifiable tracheostomy indications, which introduces a possible case selection bias. However, the limitations of early randomization are demonstrated by randomized trials investigating early tracheostomy in critically ill patients, as they show that more than $50 \%$ of late tracheostomy cases do not undergo a tracheostomy. Second, as sedatives should be used very cautiously in patients with brainstem lesions due to possible respiration-depressing side effects, we did not evaluate the impact of tracheostomy timing on the use of sedatives. Third, in our study, all the patients underwent elective tracheostomy, and most patients underwent percutaneous tracheostomy. Because of the contraindications for percutaneous tracheostomy, only 18 patients underwent open surgical tracheotomy, which were performed by otorhinolaryngological surgeons for security reasons. However, it should be mentioned 
that an open surgical tracheotomy generally requires surgical closure of the stoma after decannulation and the open surgical tracheotomy should only be performed for compelling medical reasons and not depending on the specialist discipline.

\section{Conclusions}

Although early tracheostomy timing was not associated with a significant improvement in hospital mortality or neurological outcomes in patients undergoing resection of infratentorial lesions, it decreased respiratory complications and ICU LOS as well as facilitated decannulation. Earlier performance of tracheostomy might be recommended in the clinical practice, especially in patients with risk factors. Given the difficult assessment of early tracheostomy indications, our results may reveal an actual benefit of early tracheostomy.

Authors' contribution All authors have contributed significantly to the study design, analyses, interpretation of the data, and writing of the manuscript.

Funding information This work was supported by the National Natural Science Foundation of China [grant number 81801042] and the Beijing Municipal Administration of Hospitals Youth Programme [grant number 20190504]. The funder had no role in the study design, data collection and analysis, decision to publish, or manuscript preparation.

Data availability The datasets used and/or analyzed during the current study are available from the corresponding author on reasonable request.

\section{Compliance with ethical standards}

Conflicts of interest The authors declare that they have no conflicts of interest.

Ethics approval The study was approved by the Institutional Review Board of Bejing Tiantan Hospital, Capital Medical University, Beijing, China.

Consent to participate Patient informed consents were waived due to the retrospective nature of the study.

Consent for publication Not applicable.

\section{References}

1. Flexman AM, Merriman B, Griesdale DE, Mayson K, Choi PT, Ryerson CJ (2014) Infratentorial neurosurgery is an independent risk factor for respiratory failure and death in patients undergoing intracranial tumor resection. J Neurosurg Anesthesiol 26:198-204. https://doi.org/10.1097/ANA.0b013e3182a43ed8

2. Qureshi AI, Suarez JI, Parekh PD, Bhardwaj A (2000) Prediction and timing of tracheostomy in patients with infratentorial lesions requiring mechanical ventilatory support. Crit Care Med 28:13831387. https://doi.org/10.1097/00003246-200005000-00020
3. Gessler F, Mutlak H, Lamb S, Hartwich M, Adelmann M, Platz J, Konczalla J, Seifert V, Senft C (2015) The impact of tracheostomy timing on clinical outcome and adverse events in poor-grade subarachnoid hemorrhage. Crit Care Med 43:2429-2438. https://doi. org $/ 10.1097 / \mathrm{ccm} .0000000000001195$

4. Bosel J, Schiller P, Hook Y et al (2013) Stroke-related early tracheostomy versus prolonged orotracheal intubation in neurocritical care trial (SETPOINT): a randomized pilot trial. Stroke 44:21-28. https://doi.org/10.1161/strokeaha.112.669895

5. Siempos II, Ntaidou TK, Filippidis FT, Choi AMK (2015) Effect of early versus late or no tracheostomy on mortality and pneumonia of critically ill patients receiving mechanical ventilation: a systematic review and meta-analysis. Lancet Respir Med 3:150-158. https:// doi.org/10.1016/s2213-2600(15)00007-7

6. Shibahashi K, Sugiyama K, Houda H, Takasu Y, Hamabe Y, Morita A (2017) The effect of tracheostomy performed within $72 \mathrm{~h}$ after traumatic brain injury. Br J Neurosurg 31:564-568. https://doi.org/10.1080/02688697.2017.1302071

7. Bosel J (2017) Use and timing of tracheostomy after severe stroke. Stroke 48:2638-2643. https://doi.org/10.1161/strokeaha.117. 017794

8. Goriachev AS, Savin IA, Gorshkov KM, Konkov MN, Ol'khina EV, Volkova MV (2004) Early tracheostomy in patients with tumors in the posterior cranial fossa during postoperative period. Anesteziol Reanimatol 2004:58-60

9. Boles JM, Bion J, Connors A, Herridge M, Marsh B, Melot C, Pearl R, Silverman H, Stanchina M, Vieillard-Baron A, Welte T (2007) Weaning from mechanical ventilation. Eur Respir J 29:1033-1056. https://doi.org/10.1183/09031936.00010206

10. Wu YX, Chen H, Li Q, Hao JJ, Zhao LH, He X, Sun XM, Xu M, Zhou JX (2017) The prophylactic use of remifentanil for delayed extubation after elective intracranial operations: a prospective, randomized, double-blinded trial. J Neurosurg Anesthesiol 29:281290. https://doi.org/10.1097/ana.0000000000000311

11. Coplin WM, Pierson DJ, Cooley KD, Newell DW, Rubenfeld GD (2000) Implications of extubation delay in brain-injured patients meeting standard weaning criteria. Am J Respir Crit Care Med 161:1530-1536. https://doi.org/10.1164/ajrccm.161.5.9905102

12. Jeon YT, Hwang JW, Lim YJ, Lee SY, Woo KI, Park HP (2014) Effect of tracheostomy timing on clinical outcome in neurosurgical patients: early versus late tracheostomy. J Neurosurg Anesthesiol 26:22-26. https://doi.org/10.1097/ANA.0b013e31829770a0

13. Young D, Harrison DA, Cuthbertson BH, Rowan K (2013) Effect of early vs late tracheostomy placement on survival in patients receiving mechanical ventilation: the TracMan randomized trial. JAMA. 309:2121-2129. https://doi.org/10.1001/jama.2013.5154

14. Terragni PP, Antonelli M, Fumagalli R, Faggiano C, Berardino M, Pallavicini FB, Miletto A, Mangione S, Sinardi AU, Pastorelli M, Vivaldi N, Pasetto A, Della Rocca G, Urbino R, Filippini C, Pagano E, Evangelista A, Ciccone G, Mascia L, Ranieri VM (2010) Early vs late tracheotomy for prevention of pneumonia in mechanically ventilated adult ICU patients: a randomized controlled trial. JAMA 303:1483-1489. https://doi.org/10.1001/jama.2010.447

15. McCann MR, Hatton KW, Vsevolozhskaya OA, Fraser JF (2019) Earlier tracheostomy and percutaneous endoscopic gastrostomy in patients with hemorrhagic stroke: associated factors and effects on hospitalization. J Neurosurg 2019:1-7. https://doi.org/10.3171/ 2018.7.Jns181345

16. Chen W, Liu F, Chen J, Ma L, Li G, You C (2019) Timing and outcomes of tracheostomy in patients with hemorrhagic stroke. World Neurosurg 131:e606-e613. https://doi.org/10.1016/j.wneu. 2019.08.013

17. Blot F, Similowski T, Trouillet JL, Chardon P, Korach JM, Costa MA, Journois D, Thiéry G, Fartoukh M, Pipien I, Bruder N, Orlikowski D, Tankere F, Durand-Zaleski I, Auboyer C, Nitenberg G, Holzapfel L, Tenaillon A, Chastre J, Laplanche A 
(2008) Early tracheotomy versus prolonged endotracheal intubation in unselected severely ill ICU patients. Intensive Care Med 34: 1779-1787. https://doi.org/10.1007/s00134-008-1195-4

18. Rumbak MJ, Newton M, Truncale T, Schwartz SW, Adams JW, Hazard PB (2004) A prospective, randomized, study comparing early percutaneous dilational tracheotomy to prolonged translaryngeal intubation (delayed tracheotomy) in critically ill medical patients. Crit Care Med 32:1689-1694. https://doi.org/10. 1097/01.ccm.0000134835.05161.b6

19. Dunham CM, LaMonica C (1984) Prolonged tracheal intubation in the trauma patient. J Trauma 24:120-124. https://doi.org/10.1097/ 00005373-198402000-00005

20. Chesnut RM, Temkin N, Carney N, Dikmen S, Rondina C, Videtta W, Petroni G, Lujan S, Pridgeon J, Barber J, Machamer J, Chaddock K, Celix JM, Cherner M, Hendrix T (2012) A trial of intracranial-pressure monitoring in traumatic brain injury. N Engl J Med 367:2471-2481. https://doi.org/10.1056/NEJMoa1207363

21. Godet T, Chabanne R, Marin J, Kauffmann S, Futier E, Pereira B, Constantin JM (2017) Extubation failure in brain-injured patients: risk factors and development of a prediction score in a preliminary prospective cohort study. Anesthesiology 126:104-114. https://doi. org/10.1097/aln.0000000000001379

22. Guru PK, Singh TD, Pedavally S, Rabinstein AA, Hocker S (2016) Predictors of extubation success in patients with posterior fossa strokes. Neurocrit Care 25:117-127. https://doi.org/10.1007/ s12028-016-0249-7

23. Vallverdu I, Calaf N, Subirana M, Net A, Benito S, Mancebo J (1998) Clinical characteristics, respiratory functional parameters, and outcome of a two-hour T-piece trial in patients weaning from mechanical ventilation. Am J Respir Crit Care Med 158:18551862. https://doi.org/10.1164/ajrccm.158.6.9712135

24. Namen AM, Ely EW, Tatter SB et al (2001) Predictors of successful extubation in neurosurgical patients. Am J Respir Crit Care Med 163:658-664. https://doi.org/10.1164/ajrccm.163.3.2003060

25. Manno EM, Rabinstein AA, Wijdicks EF et al (2008) A prospective trial of elective extubation in brain injured patients meeting extubation criteria for ventilatory support: a feasibility study. Crit Care 12:R138. https://doi.org/10.1186/cc7112

26. Asehnoune K, Seguin P, Lasocki S, Roquilly A, Delater A, Gros A, Denou F, Mahé PJ, Nesseler N, Demeure-dit-Latte D, Launey Y, Lakhal K, Rozec B, Mallédant Y, Sébille V, Jaber S, le Thuaut A, Feuillet F, Cinotti R, Blanloeil Y (2017) Extubation success prediction in a multicentric cohort of patients with severe brain injury. Anesthesiology 127:338-346. https://doi.org/10.1097/aln. 0000000000001725

27. Jaber S, Quintard H, Cinotti R, Asehnoune K, Arnal JM, Guitton C, Paugam-Burtz C, Abback P, Mekontso Dessap A, Lakhal K, Lasocki S, Plantefeve G, Claud B, Pottecher J, Corne P, Ichai C, Hajjej Z, Molinari N, Chanques G, Papazian L, Azoulay E, de Jong A (2018) Risk factors and outcomes for airway failure versus nonairway failure in the intensive care unit: a multicenter observational study of 1514 extubation procedures. Crit Care 22:236. https://doi. org/10.1186/s13054-018-2150-6

28. Shaw JJ, Santry HP (2015) Who gets early tracheostomy?: evidence of unequal treatment at 185 academic medical centers. Chest 148: 1242-1250. https://doi.org/10.1378/chest.15-0576

29. Holevar M, Dunham JC, Brautigan R et al (2009) Practice management guidelines for timing of tracheostomy: the EAST Practice Management Guidelines Work Group. J Trauma 67:870-874. https://doi.org/10.1097/TA.0b013e3181b5a960

30. BouAkl I, Bou-Khalil P, Kanazi G, Ayoub C, El-Khatib M (2012) Weaning from mechanical ventilation. Curr Opin Anaesthesiol 25: 42-47. https://doi.org/10.1097/ACO.0b013e32834e6430

31. Bickenbach J, Fries M, Offermanns V, von Stillfried R, Rossaint R, Marx G, Dembinski R (2011) Impact of early vs. late tracheostomy on weaning: a retrospective analysis. Minerva Anestesiol 77:11761183

32. McCredie VA, Alali AS, Scales DC et al (2017) Effect of early versus late tracheostomy or prolonged intubation in critically ill patients with acute brain injury: a systematic review and meta-analysis. Neurocrit Care 26:14-25. https://doi.org/10.1007/s12028016-0297-z

33. Andriolo BN, Andriolo RB, Saconato H, Atallah AN, Valente O (2015) Early versus late tracheostomy for critically ill patients. Cochrane Database Syst Rev 1:Cd007271. https://doi.org/10. 1002/14651858.CD007271.pub3

34. Szakmany T, Russell P, Wilkes AR, Hall JE (2015) Effect of early tracheostomy on resource utilization and clinical outcomes in critically ill patients: meta-analysis of randomized controlled trials. Br J Anaesth 114:396-405. https://doi.org/10.1093/bja/aeu440

35. Hosokawa K, Nishimura M, Egi M, Vincent JL (2015) Timing of tracheotomy in ICU patients: a systematic review of randomized controlled trials. Crit Care 19:424. https://doi.org/10.1186/s13054015-1138-8

36. Cook DJ, Montori VM, McMullin JP, Finfer SR, Rocker GM (2004) Improving patients' safety locally: changing clinician behaviour. Lancet 363:1224-1230. https://doi.org/10.1016/s01406736(04) $15955-2$

37. Kocaeli H, Korfali E, Taskapilioglu O, Ozcan T (2008) Analysis of intracranial pressure changes during early versus late percutaneous tracheostomy in a neuro-intensive care unit. Acta Neurochir 150: 1263-1267; discussion 1267. https://doi.org/10.1007/s00701-0080153-9

38. Stocchetti N, Parma A, Lamperti M, Songa V, Tognini L (2000) Neurophysiological consequences of three tracheostomy techniques: a randomized study in neurosurgical patients. J Neurosurg Anesthesiol 12:307-313. https://doi.org/10.1097/00008506200010000-00002

Publisher's note Springer Nature remains neutral with regard to jurisdictional claims in published maps and institutional affiliations. 